\title{
A STUDY OF ETIOPATHOLOGY AND OUTCOIMES IN CASES OF NECK ABSCESSES AND TREATMENT MODALITIES IN A TERTIARY CARE CENTRE
}

KEY WORDS: Neck abscess, Comorbidities, Etiologies, Treatment.

\section{Dr Arijit Chatterjee \\ Dr Souradeep Ray}

Dr Jayanta Saha

\section{Dr Bipasa} Chakraborty

\section{Dr Debabrata} Biswas*
Senior Resident, Department Of ENT \&HEAD NECK SURGERY, R.G.Kar Medical College and Hospital.

Associate Professor, Department of ENT \& HEAD NECK SURGERY, Burdwan Medical College and Hospital.

Associate Professor, Department of ENT \& HEAD NECK SURGERY, R.G.Kar Medical College and Hospital.

Assistant Professor, Department of Microbiology, R.G.Kar Medical College and Hospital.

Assistant Professor, Department of ENT \& HEAD NECK SURGERY , R.G.Kar Medical College and Hospital. *Corresponding Author

Background: Neck abscess is infection of potential spaces of throat with bacterial pathogens which may present diagnostic difficulties and lead to serious complications. Most deep neck infections arise from foci in the mucosal surfaces of the upper aerodigestive tract or from a carious tooth. Usually associated unregulated comorbidities play a major role in advancement of the disease process.Treatment decision relies on the extent and severity of neck abscesses. The aim of the present study was to correlate neck abscesses and etiologies with comorbidities and various treatment modalities for these cases.

Aims and Objectives of the Study:

Aims OfThe Study. -

1. To do a prospective etiopathological analysis and outcomes of neck abscesses among patients attending IPD of a tertiary care centre.

2. To evaluate various treatment modalities in the patients of neck abscesses.

Objective OfThe Study-

A proper way to deal with those cases can be understood and can be followed.

Methodology: A prospective study was performed in 90 cases of neck abscesses in a tertiary care hospital for a period of 1.5years from February 2019 to July 2020.Association between neck abscesses with etiological factors, disease outcomes and various treatment modalities were noted.

Result: It is better understood that unregulated comorbidities play major role associated with all tilogical factors in formation of neck abscesses and meticulous management of all etiological factors and comorbidities are the proper way to deal with a case of neck abscess through multidisciplinary apporoaches.

\section{INTRODUCTION}

Before the widespread use of antibiotics, $70 \%$ of deep neck space infections were caused by spread from tonsillar and pharyngeal infections. Today, tonsillitis remains the most common etiology of deep neck space infections in children whereas odontogenic origin is the most common etiology in adults. ${ }^{1,2}$. Study by Adovi $\square$ a et al found that out of 263 patients hospitalized for deep neck space phlegmons and/or abscesses, $70.6 \%$ of the cases arised from dental infections ${ }^{3}$.

\section{Causes of deep neck infections include the following:}

- Tonsillar and pharyngeal infections

- Dental infections or abscesses

- Oral surgical procedures or removal of suspension wires

- Salivary gland infection or obstruction

- Trauma to the oral cavity and pharynx (eg, gunshot wounds, pharynx injury caused by falls onto pencils or Popsicle sticks, esophageal lacerations from ingestion of fish bones or other sharp objects)

- Instrumentation, particularly from esophagoscopy or bronchoscopy

- Foreign body aspiration

- Cervical lymphadenitis

- Thyroiditis

- Mastoiditis with petrous apicitis and Bezold abscess

- Laryngopyomucocele

- IV drug use

- Necrosis and suppuration of a malignant cervical lymph node or mass $20-50 \%$ of deep neck infections have no identifiable source.
Other important considerations include patients who are immunosuppressed because of human immunodeficiency virus (HIV) infection, chemotherapy or immunosuppressant drugs for transplantation and unregulated comorbidities like diabetes. These patients may have increased frequency of deep neck infections and atypical organisms and they may have more frequent complications.

A retrospective study by Alotaibi et al indicated that in patients with odontogenic infection, criteria for hospital admission based on a risk of deep neck space infection should include not just the well-known risk signs-fever, trismus, leukocytosis, swollen neck, dysphagia, dyspnea, and elevated C-reactive protein levels-but also the presence of mandibular (as opposed to maxillary) odontogenic infection and/or dental abscess. The study included a cohort of 97 patients.

Systemic lupus erythematosus (SLE) may be another etiologic factor in deep neck space infection. A retrospective study by Chang et al indicated that individuals with SLE have an approximately five-fold greater risk of developing the condition.

The management of deep neck infections is challenging and should be carried out by an interdisciplinary team. The prognosis of deep neck infections depends on the comorbidities of the patient such as diabetes mellitus, alcoholism or drug abuse ${ }^{6}$. Computer tomography (CT-scan) of the head and neck and the upper thorax is the most 
common tool for diagnosis ${ }^{7}$.

Since most deep neck infections are considered surgical emergencies, there are no randomized trials to determine the best procedure, antibiotic or duration of treatment. The only definitive data is that surgery is recommended in almost all patients with neck abscess. The earlier the surgery, the better the outcomes.

Neck abscesses can be difficult to drain and have fatal consequences if not timely diagnosed, accurately localised and promptly incised and drained. Yet the management is commonly left in the hands of surgical trainees.

\section{Aims and Objectives of the Study: \\ AIMS OF THE STUDY}

1. To do a prospective etiopathological analysis and outcomes of neck abscesses among patients attending IPD of a tertiary care centre.

2. To evaluate various treatment modalities in the patients of neck abscesses.

\section{Objective OfThe Study}

A proper way to deal with those cases can be understood and can be followed.

\section{METHODOLOGY}

The prospective study has been conducted over a period of 1.5years (From February 2019 to July 2020)in the Department of ENT and Head Neck surgery in a Tertiary Care Cente. Total patients studied during the period was 90 .

Inclusion Criteria: Patients presenting with clinical features of neck abscess like Difficulty in Swallowing, Pain, Fever, Difficulty in Breathing, Torticollis, Trismus, Difficulty in moving neck etc and diagnosed with prior imaging and FNAC where indicated.

\section{Exclusion Criteria:}

1. Age more than $70 y e a r s$.

2. Children less then 5years of age.

3. Swelling of neck other than neck abscess diagnosed by prior imaging and fnac where feasible.

\section{Laboratory Investigations:}

1. Complete blood count and serum electrolytes.

2. Aspirated pus for culture and sensitivity.

3. Pus for AFB stain and CBNAAT.

4. Blood sugar (fbs, ppbs, random).

5. Lipid profile and Liver Function Tests.

6. Blood for serological studies for HIV, Hepatitis C and Hepatitis B.

\section{Parameters Studied:}

- Incidence of Neck Abscess in each anatomical neck spaces among the study sample patients.

- Demographic characters of the study population and socioeconomic status as per B.G.Prasad's classification.

- Imaging characteristics (X-RAY, USG, CT or MRI) of Neck Abscesses (site of abscess and/or complications).

- Association of comorbities like Diabetes, Immunodeficiency, Steroid therapy, Chemotherapy, Dyslipidemia and Hypertension.

- Treatments used and outcomes of treatment protocols in patients.

\section{RESULTS AND ANALYSIS}

Table 1(Distribution of Age in Year) $\mathbf{n}=90$

\begin{tabular}{|c|c|c|}
\hline Age In Years & Number of Patients & Percentage \\
\hline$\leq 10$ & 5 & 5.6 \\
\hline $11-20$ & 10 & 11.1 \\
\hline $21-30$ & 14 & 15.6 \\
\hline $31-40$ & 13 & 14.4 \\
\hline $41-50$ & 20 & 22.2 \\
\hline $51-60$ & 18 & 20.0 \\
\hline $61-70$ & 10 & 11.1 \\
\hline Total & 90 & 100.0 \\
\hline
\end{tabular}

In the study, 20(22.2/100) patients were 41-50 years old, $18(20.0 / 100)$ patients were $51-60$ years old. 5(5.6/100) patients were $\leq 10$ years old, $10(11.1 / 100)$ patients were 11 20years old, 14(15.6/100) patients were 21-30years old, $13(14.4 / 100)$ patients were $31-40$ years old and $10(11.1 / 100)$ patient were 61-70years old.

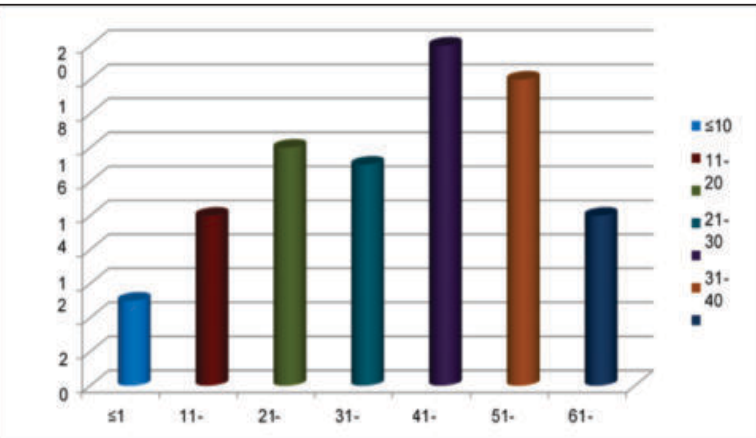

Table 2(Sex Distribution) $\mathrm{n}=90$

\begin{tabular}{|c|c|c|}
\hline SEX & Number of Patients & Percentage \\
\hline Female & 26 & $28.9 \%$ \\
\hline Male & 64 & $71.1 \%$ \\
\hline Total & 90 & $100.0 \%$ \\
\hline
\end{tabular}

In the study, 64(71.1\%) patient were Males and 26(28.9\%) patients were Females.

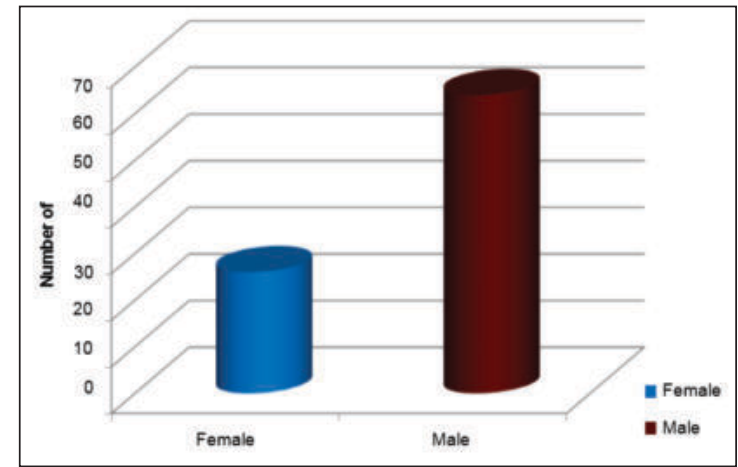

Table 3 (Socioeconomic status of the Study Population), $\mathrm{n}=90$

\begin{tabular}{|c|c|c|}
\hline Socioeconomic Status & $\begin{array}{c}\text { Number of } \\
\text { Patients }\end{array}$ & Percentage \\
\hline Upper class(uc) & 5 & 5.56 \\
\hline Upper Middle Class(UMC) & 6 & 6.67 \\
\hline Middle Class(MC) & 7 & 7.78 \\
\hline Lower Middle Class(LMC) & 22 & 24.44 \\
\hline Lower Class(LC) & 50 & 55.56 \\
\hline Total & 90 & 100 \\
\hline
\end{tabular}

In the study, it was found that 50 out of 90 patients $(55.56 \%)$ belonged to lower class and 22 out of 90 patients $(24.44 \%)$ belonged to lower middle class.5 out of 90patients(5.56\%) belonged to upper class, 6 out of 90 patients $(6.67 \%)$ belonged to upper middle class, 7 out of 90 patients(7.78\%) belonged to middle class.

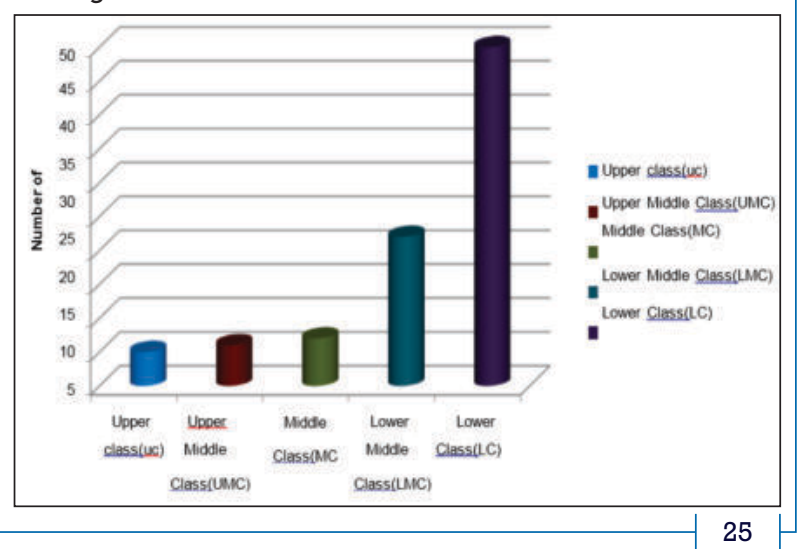


PARIPEX - INDIAN JOURNAL OF RESEARCH | Volume - 10 | Issue - 12 |December - 2021 | PRINT ISSN No. 2250 - 1991 | DOI : $10.36106 /$ paripex

Table 4(Distribution of Etiologies) $n=90$

\begin{tabular}{|c|c|c|c|}
\hline Etiology & Present & Absent & Percent \\
\hline ODONTOGENIC & 44 & 48 & $48.89 \%$ \\
\hline URTI & 20 & 70 & $22.22 \%$ \\
\hline SALIVARY GLAND INFECTION & 3 & 87 & $3.33 \%$ \\
\hline TRAUMA TO NECK & 2 & 88 & $2.22 \%$ \\
\hline FOREIGN BODY & 1 & 89 & $1.11 \%$ \\
\hline INSTRUMENTATION & 2 & 88 & $2.22 \%$ \\
\hline TUBERCULOSIS & 3 & 87 & $3.33 \%$ \\
\hline INFECTED CYSTS & 0 & 90 & $0.00 \%$ \\
\hline UNKNOWN CAUSE & 15 & 75 & $16.67 \%$ \\
\hline
\end{tabular}

In the study, 44(48.89\%) patients had Odontogenic Infection, $20(22.22 \%)$ patients had URTI.

$3(3.33 \%)$ patients had Salivary Gland Infection, $2(2.22 \%)$ patients had Trauma to Neck, l(1.11\%) patients had Foreign Body, 2(2.22\%) patients had Instrumentation, 3(3.33\%) patients had Tuberculosis and $15(16.67 \%)$ patient had Unknown etiologies.

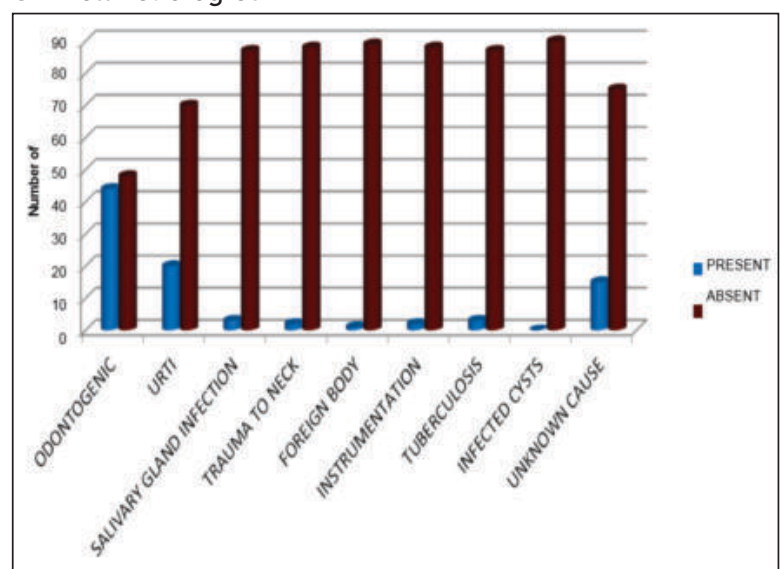

Table 5 (neck Space Involvements) N=90

\begin{tabular}{|c|c|c|c|}
\hline Neck Space Involved & Present & Absent & $\begin{array}{c}\text { Incidence among } \\
\text { study population } \\
\text { per } \mathbf{1 0 0}\end{array}$ \\
\hline PARAPHARYNGEAL & 44 & 46 & 48.9 \\
\hline SUBMANDIBULAR & 50 & 40 & 55.6 \\
\hline PAROTID & 9 & 81 & 10.0 \\
\hline RETROPHARYNGEAL & 15 & 75 & 16.7 \\
\hline PREVERTEBRAL & 3 & 87 & 3.33 \\
\hline PERITONSILLAR & 13 & 77 & 14.44 \\
\hline MASTICATOR/ & 9 & 81 & 10.0 \\
\hline TEMPORAL & & & \\
\hline PRETRACHEAL & 7 & 83 & 7.78 \\
\hline BUCCAL & 0 & 90 & 0.00 \\
\hline CAROTID & 1 & 89 & 1.11 \\
\hline SUBMENTAL & 13 & 77 & 14.44 \\
\hline CANINE & 0 & 90 & 0.00 \\
\hline MULTIPLE SPACES & 48 & 42 & 53.33 \\
\hline
\end{tabular}

In the study, 50(55.6\%) patients had Submandibular abscess and $44(48.9 \%)$ patients had Parapharyngeal abscess. $48(53.33 \%)$ patients had Multiple Spaces involved in abscess.

9(10.0\%) patients had Parotid abscess, $15(16.7 \%)$ patients had Retropharyngeal abscess, 3 (3.33\%) patients had Prevertebral abscess, 13(14.44\%) patients had Peritonsillar abscess, $9(10.0 \%)$ patients had Masticator/temporal abscess, $7(7.78 \%)$ patients had Pretracheal abscess, $1(1.11 \%)$ patients had Carotid abscess, 13(14.44\%) patients had Submental abscess.

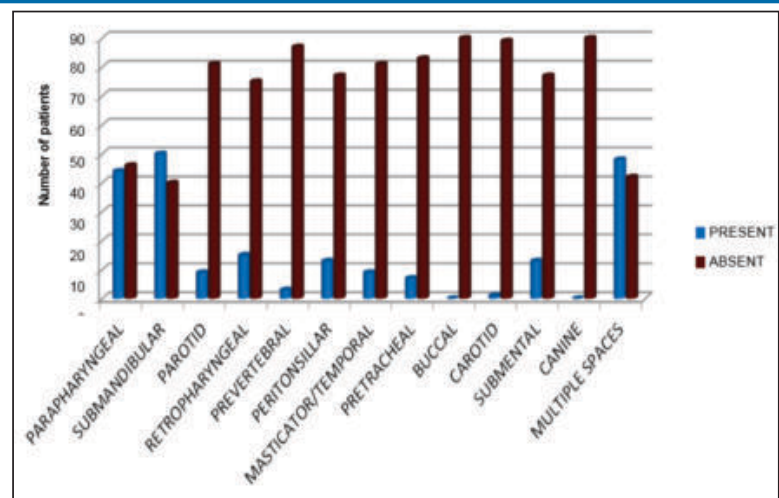

Table 6(Associated Comorbidities) $\mathrm{n}=90$

\begin{tabular}{|c|c|c|c|}
\hline Comorbidity & Present & Absent & Percentage \\
\hline DIABETES & 35 & 55 & $38.9 \%$ \\
\hline HYPERTENSION & 17 & 73 & $18.9 \%$ \\
\hline DYSLIPIDAEMIA & 10 & 80 & $11.11 \%$ \\
\hline HIV & 4 & 86 & $4.44 \%$ \\
\hline HEPATITS B & 3 & 87 & $3.33 \%$ \\
\hline HEPATITIS C & 0 & 90 & $0.00 \%$ \\
\hline $\begin{array}{c}\text { CHRONIC KIDNEY } \\
\text { DISEASE(CKD) }\end{array}$ & 5 & 85 & $5.56 \%$ \\
\hline CARDIAC DISEASE & 5 & 85 & $5.56 \%$ \\
\hline $\begin{array}{c}\text { CHRONIC LIVER } \\
\text { DISEASE(CLD) }\end{array}$ & 9 & 81 & $10 \%$ \\
\hline CHEMOTHERAPY & 0 & 90 & $0.00 \%$ \\
\hline STEROID THERAPY & 0 & 90 & $0.00 \%$ \\
\hline MULTIPLE & 29 & 61 & $32.22 \%$ \\
\hline NO COMORBIDITY & 40 & 50 & $44.44 \%$ \\
\hline
\end{tabular}

In Comorbidity Group, 35(38.9\%) patients had Diabetes and $28(32.22 \%)$ patients had Multiple comorbidities.

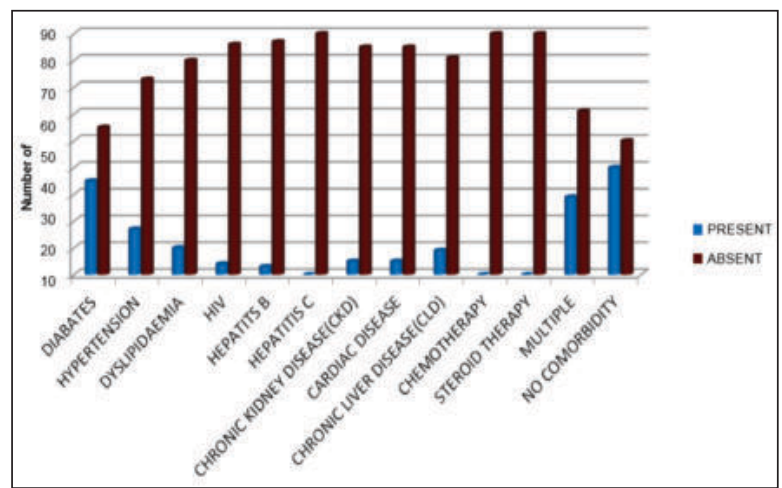

Table 7(associated Complications), $\mathbf{N}=90$

\begin{tabular}{|c|c|c|c|}
\hline Complications & Present & Absent & Percentage \\
\hline AIRWAY OBSTRUCTION & 10 & 80 & $11.11 \%$ \\
\hline SKIN CHANGES & 52 & 38 & $57.8 \%$ \\
\hline PNEUMONIA & 6 & 84 & $6.67 \%$ \\
\hline SEPSIS & 5 & 85 & $5.56 \%$ \\
\hline MEDIASTINITIS & 3 & 87 & $3.33 \%$ \\
\hline MIXED & 16 & 74 & $17.8 \%$ \\
\hline NONE & 30 & 60 & $33.33 \%$ \\
\hline
\end{tabular}

Among Complications, 52(57.8\%) patients had Skin Changes, $10(11.11 \%)$ patients had Airway Obstruction, 6(6.67\%) patients had Pneumonia, 5(5.56\%) patients had Sepsis, $3(3.33 \%)$ patients had Mediastinitis and $16(17.8 \%)$ patient had Mixed complications.

Table 8 (management Modalities) $\mathbf{N}=90$

\begin{tabular}{|c|c|c|}
\hline Management modalities & Number & Percentage \\
\hline Only Medical & 14 & $15.56 \%$ \\
\hline $\begin{array}{c}\text { Incision \& drainage+ medical } \\
\text { management }\end{array}$ & 51 & $56.7 \%$ \\
\hline
\end{tabular}

|www.worldwidejournals.com $\mid$ 


\begin{tabular}{|c|c|c|}
\hline Incision\& drainage+ tracheostomy & 3 & $3.33 \%$ \\
\hline $\begin{array}{c}\text { Incision \& drainage } \\
+ \text { tracheostomy+ tooth extraction }\end{array}$ & 4 & $4.44 \%$ \\
\hline $\begin{array}{c}\text { Incision \& drainage+ tooth } \\
\text { extraction }\end{array}$ & 15 & $16.67 \%$ \\
\hline Medical+tooth extraction & 3 & $3.33 \%$ \\
\hline
\end{tabular}

In Management modalities , 51(56.7\%) patients had Incision \& drainage +medical management.14(15.56\%) patients had Only Medical, 3(3.33\%) patients had Incision \& drainage+ tracheostomy, 4(4.44\%) patients had Incision \& drainage + tracheostomy + tooth extraction, 15(16.67\%) patients had Incision \& drainage+ tooth extraction and $4(3.33 \%)$ patients had Medical management + tooth extraction.In this all observations comorbid patients were managed for their comorbidities as perWHO guidelines.

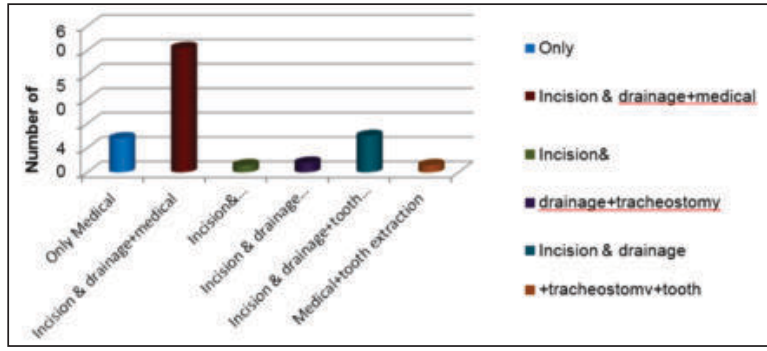

Table 9 (Complete Blood profile, Liver fuction tests and Serum electrolyte level)

Total neck abscess patients $(n)=90$

\begin{tabular}{|c|c|c|c|}
\hline FINDINGS & PRESENT & ABSENT & $\begin{array}{c}\text { PERCENTAGE OF } \\
\text { PRESENCE OF } \\
\text { LEUKOCYTOSIS }\end{array}$ \\
\hline LEUKOCYTOSIS & 88 & 2 & 97.78 \\
\hline
\end{tabular}

It is found that $97.78 \%$ patients of neck abscess had leukocytosis.

Total Chronic Liver disease (CLD) patients found in the study (n) $=9$

\begin{tabular}{|c|c|c|c|}
\hline FINDINGS & NORMAL & DERANGED & $\begin{array}{c}\text { PERCENTAGE } \\
\text { OF } \\
\text { DERANGED }\end{array}$ \\
\hline $\begin{array}{c}\text { LIVER FUNCTION } \\
\text { TESTS AMONG } \\
\text { CLD PATIENTS }\end{array}$ & 0 & 9 & $100 \%$ \\
\hline
\end{tabular}

It is found that all CLD patients in this study had deranged liver function test.

Total multiple comorbid patients $(n)=29$

\begin{tabular}{|c|c|c|c|}
\hline FINDING & NORMAL & DERANGED & $\begin{array}{c}\text { PERCENTAGE OF } \\
\text { DERANGED }\end{array}$ \\
\hline $\begin{array}{c}\text { SERUM } \\
\text { ELECTROLYTE } \\
\text { LEVEL }\end{array}$ & 23 & 6 & 20.69 \\
\hline
\end{tabular}

It is seen that among patients having multiple comorbidities, $20.69 \%$ patients had deranged serum electrolyte levels. These patients constitute mostly comorbidities of hypertension, diabetes mellitus, chronic kidney disease and cardiac diseases.

Table 10 (Significant Association between Comorbidities and Neck abscesses)

Total Patients of Neck Abscess With Comorbidities (n) $=50$

\begin{tabular}{|l|l|l|l|}
\hline Comorbidity & Present & Absent & P value \\
\hline Diabetes & 35 & 15 & 0.00006 \\
\hline
\end{tabular}

In the study it is found that among comorbid patients, Diabetes has a significant association with neck abscess formation ( $p$ value significant at $<0.05$ with chi square test).

Table 11 (Significant Association between Comorbidities and Complications in patients with Neck abscesses)

\begin{tabular}{|l|l|l|l|}
\hline Comorbidity & $\begin{array}{l}\text { Complication } \\
\text { present }\end{array}$ & $\begin{array}{l}\text { Complication } \\
\text { absent }\end{array}$ & P value \\
\hline Diabetics $(n=35)$ & 26 & 9 & 0.0005 \\
\hline $\begin{array}{l}\text { Multiple } \\
\text { comorbidities }(n=29)\end{array}$ & 23 & 6 & 0.0001 \\
\hline
\end{tabular}

In the study, diabetic patients have a significant association with formation of complications in neck abscess ( $p$ value significant at $<0.05$ with chi square test). Also patients presenting with multiple comorbidities have significant association with formation of complications of neck abscess ( $\mathrm{p}$ value significant at 0.0001 with chi square test).

Table 12 (Significant Association between Management modalities and Neck abscess)

Total neck abscess patient $=90$

\begin{tabular}{|c|c|c|c|}
\hline & $\begin{array}{c}\text { Incision\& drainage } \\
\text { required }\end{array}$ & $\begin{array}{c}\text { Medical } \\
\text { management }\end{array}$ & P value \\
\hline $\begin{array}{c}\text { Total neck } \\
\text { abscess } \\
\text { patients }(n=90)\end{array}$ & 73 & 17 & 0.0001 \\
\hline
\end{tabular}

In this study it is found that Incision \& Drainage modality is a significant treatment modality for neck abscess patients rather than medical management alone ( $p$ value significant at $<0.05$ with chi square test).

\section{DISCUSSION}

The study was performed with 90 patients of neck abscess to find out etiopathological correlation. In the study, Male patients were $64(71.1 \%)$ and $26(28.9 \%)$ patients were Female. More vulnerability to deep neck space infections are due to higher rate of odontogenic and upper respiratory tract infectivity and comorbidities which are more commonly seen in males than females so susceptibility of neck abscess formation is also more commonly seen in males. Brito TP et al ${ }^{9}$ (2017) also in his study found that there was predominance in the male gender (55.5\%) and young people (mean age 28.1 years) in neck abscess cases. In our study, 20(22.2/100) patients were 41-50 years old, 18(20.0/100) patients were 5160 years old. Huang TT et al ${ }^{10}$ (2004) studied 185 patients; 109 $(58.9 \%)$ were males and $76(41.1 \%)$ were females with a mean age of $49.5 \pm 20.5$ years. Ninety seven $(52.4 \%)$ of the patients in his study were older than 50 years of age.

In our study, we found that 50 out of 90 patients $(55.56 \%)$ belonged to lower class and 22 out of 90 patients $(24.44 \%)$ belonged to lower middle class. 5 out of 90 patients(5.56\%) belonged to upper class, 6 out of 90 patients $(6.67 \%)$ belonged to upper middle class, 7 out of 90 patients(7.78\%) belonged to middle class. Lower class persons are more susceptible to infections due to unhygienic practices in daily life and also due to prevalence of unchecked comorbidities. Agarwal AK et al ${ }^{11}$ (2007) in his study assessed the socioeconomic factors, presentation, aetiological factors, microbiology and management of deep neck space abscesses. Most of the patients were of low socioeconomic status in his study.

In our study, 44(48.89\%) patients had Odontogenic Infection, $20(22.22 \%)$ patients had URTI. $3(3.33 \%)$ patients had Salivary Gland Infection, 2(2.22\%) patients had Trauma to Neck, $1(1.11 \%)$ patients had Foreign Body, $2(2.22 \%)$ patients had Instrumentation, $3(3.33 \%)$ patients had Tuberculosis and $15(16.67 \%)$ patient had Unknown etiologies. Vieira $\mathbf{F}$ et al ${ }^{12}$ (2008) found in his study that the most common primary sources of deep neck infection are odontogenic, tonsillar, salivary gland, foreign body and malignancy. Brito TP et al ${ }^{9}$ (2017)) showed in his study that the most frequent causes of neck space infections were bacterial tonsillitis (31.68\%) and odontogenic infections (23.7\%). 
and $44(48.9 \%)$ patients had Parapharyngeal abscess. $48(53.33 \%)$ patients had Multiple Spaces involved in abscess. Premolar, molar and Canine teeth are directly in close proximity to Submandibular and Parapharyngeal and Canine spaces so chances of spread of infectivity from dental causes to these spaces are higher. Bakir S et al $^{13}(2012)$ in his study also found the most common involved site in neck abscess formation was the submandibular space (26.1\%). In $29.5 \%$ of cases of his study, the infection involved more than one space.Among the comorbid patients in our study, 35(38.9\%) patients had Diabetes and $28(32.22 \%)$ patients had Multiple comorbidities. It is seen that among patients having multiple comorbidities, $20.69 \%$ patients had deranged serum electrolyte levels. These patients constitute mostly comorbidities of hypertension, diabetes mellitus, chronic kidney disease and cardiac diseases. In our study, among comorbid patients, Diabetes has a significant association with neck abscess formation ( $p$ value significant at $<0.05$ with chi square test). Diabetic patients have a significant association with formation of complications in neck abscess ( $p$ value significant at $<0.05$ with chi square test). Also patients presenting with multiple comorbidities have significant association with formation of complications of neck abscess ( $p$ value significant at 0.0001 with chi square test).In our study, among 4 HIV patients, all 4 developed secondary bacterial infection leading to neck abscess and all 4 patients needed Incision and Drainage of abscess. Boscolo-Rizzo P et al ${ }^{14}$

(2012) retrospectively identified 365 adult patients with Deep Neck Infections and there were 67 patients (18.4\%) developing life-threatening complications. Diabetes mellitus (odd ratio 5.43; $\mathrm{P}<0.001$ ) and multiple deep neck spaces involvement (odd ratio 4.92; $\mathrm{P}<0.001$ ) were the strongest independent predictors of complications. The mortality rate was $0.3 \%$. Airway obstruction and descending mediastinitis are the most troublesome complications of Deep Neck Infections. Nwashindi A et al ${ }^{15}$ (2019) had the objective of his study to analyze a series of patients with facial space infection associated with comorbidities. Data were collected from 98 patients with facial and deep neck space infections who met the inclusion criteria over a period of 3 years. Data included demographic information, anatomic space involved and comorbid factors. A total of 98 patients who met the inclusion criteria were investigated in this study. Diabetes mellitus (DM) was the highest comorbid factor. The patients presented mostly within 24-48 hours from the onset of infection. Chen MK et al ${ }^{16}(2000)$ also found in his observation that compared with the Non diabetic patients, the unique features of deep neck infections in diabetic patients were as follows: (1) older age, (2) tendency of unclear infection source, (3) tendency to involve multiple spaces, (4) required more aggressive surgical intervention, (5) prolonged hospitalization and (6) higher complication rate. The differences were statistically significant $(\mathrm{P}<.05)$ in his study. Overall susceptibility of body to any kind of infections are raised with uncontrolled diabetes.

In Management modalities, 51(56.7\%) patients had Incision \& drainage +medical management.14(15.56\%) patients had Only Medical, 3(3.33\%) patients had Incision\& drainage+ tracheostomy, $4(4.44 \%)$ patients had Incision \& drainage + tracheostomy + tooth extraction, $15(16.67 \%)$ patients had Incision \& drainage+ tooth extraction and $4(3.33 \%)$ patients had Medical management + tooth extraction. In this all observations comorbid patients were managed for their comorbidities as per WHO guidelines. Incision \& Drainage modality is a significant treatment modality for neck abscess patients rather than medical management alone in both comorbid and non comorbid patients in our study ( $p$ value significant at $<0.05$ with chi square test).LeeYQ et al ${ }^{17}$ (2011) reviewed patient demographics, etiology, bacteriology, systemic disease, radiology, treatment, complications and outcomes in his stiudy. 131 patients were included $(64.9 \%$ male, $35.1 \%$ female) with a median age of 51.0 years. 108
$(82.4 \%)$ patients underwent surgical drainage. All 19 patients, who had upper airway obstruction, had either a tracheostomy or intubation. Old age and Diabetes were risk factors for developing deep neck abscesses and their sequelae in his study. Airway obstruction were anticipated in multi-space and floor of mouth abscesses.

\section{CONCLUSION}

More common age groups of patients of neck abscesses are adults. Majority of the patients are males. Lower socioeconomic status plays pivotal role in disease progression. Odontogenic and Upper Respiratory Tract Infections are main predisposing factors in development of neck abscesses. Usually Submandibular and Parapharytngeal spaces are mostly involved. Diabetes and other associated comorbidities like Hypertension, Chronic liver disease, Dyslipidaemia etc aggravates severity of neck abscesses and the complications. Meticulous management of all etiological factors and comorbidities are the proper way to deal with a case of neck abscess through multidisciplinary apporoaches.

\section{REFERENCES}

1. Conrad DE, Parikh SR. Deep Neck Infections. Infect Disord Drug Targets. 2012 Feb 17.

2. Chang L, Chi H, Chiu NC, Huang FY, Lee KS. Deep neck infections in different age groups of children.J Microbiol Immunol Infect. 2010 Feb. 43(1):47-52.

3. Adovica A, Veidere L, Ronis M, Sumeraga G. Deep neck infections: review of 263 cases. Otolaryngol Pol. 2017 Oct 30.71 (5):37-42.

4. Alotaibi N, Cloutier L, Khaldoun E, Bois E, Chirat M, Salvan D. Criteria for admission of odontogenic infections at high risk of deep neck space infection. Eur Ann Otorhinolaryngol Head Neck Dis. 2015 Nov. 132 (5):261-4. [Medline].

5. Chang GH, Su YC, Lin KM, et al. Deep Neck Infection in Systemic Lupus Erythematosus Patients:Real-World Evidence.Sci Rep.2020 Mar 5.10 (1):4133.

6. Celakovsky P, Kalfert D, Tucek L, Mejzlik J, Kotulek M, Vrbacky A. Deep neck infections: risk factors for mediastinal extension. Eur Arch Otorhinolaryngol. 2014;271:1679-83.

7. Lee JK, Kim HD, Lim SC. Predisposing factors of complicated deep neck infection: an analysis of 158 cases. Yonsei Med J.2007; 48:55-62.

8. Park MJ, Kim JW, Kim Y, Lee YS, Roh JL, Choi SH, Kim SY, Nam SY. Initial Nutritional Status and Clinical Outcomes in Patients with Deep Neck Infection. Clin Exp Otorhinolaryngol.2018 Dec; 11 (4):293-300.

9. Brito TP, Hazboun IM, Fernandes FL, Bento LR, Zappelini CE, Chone CT, Crespo AN. Deep neck abscesses: study of 101 cases. Brazilian journal of otorhinolaryngology.2017 Jun; 83(3):341-8.

10. Huang TT, Liu TC, Chen PR, Tseng FY, Yeh TH, Chen YS. Deep neck infection: analysis of 185 cases. Head \& Neck: Journal for the Sciences and Specialties of the Head and Neck. 2004 Oct; 26(10):854-60.

11. Agarwal AK, Sethi A, Sethi D, Mrig S, Chopra S. Role of socioeconomic factors in deep neck abscess: A prospective study of 120 patients. British Journal of Oral and Maxillofacial Surgery. 2007 Oct 1;45(7):553-5.

12. Vieira F, Allen SM, Stocks RM, Thompson JW. Deep neck infection. Otolaryngologic Clinics of North America. 2008 Jun 1;41(3):459-83.

13. Bakir S,Tanriverdi MH, Gün R, Yorgancilar AE,Yildirim M,Tekba $\square$ G,PalanciY Meriç K, Topçu $\square$. Deep neck space infections: a retrospective review of 173 cases. American journal of otolaryngology.2012 Jan 1;33(1):56-63.

14. Boscolo-Rizzo P, Stellin M, Muzzi E, Mantovani M, Fuson R, Lupato V,Trabalzini F, Da Mosto MC. Deep neck infections: a study of 365 cases highlighting recommendations for management and treatment. European Archives of Oto-Rhino-Laryngology.2012 Apr 1;269(4):1241-9.

15. Nwashindi $\mathbb{A}$. Analysis of facial and deep neck space infections in patients with comorbidities. International Journal of Health \& Allied Sciences. $2019 \mathrm{Jan}$ $1 ; 8(1): 48$.

16. Chen MK, Wen YS, Chang CC, Lee HS, Huang MT, Hsiao HC. Deep neck infections in diabetic patients. American journal of otolaryngology. 2000 May 1;21(3):169-73.

17. Lee YQ, Kanagalingam J. Deep neck abscesses: the Singapore experience. European archives of oto-rhino-laryngology. 2011 Apr 1;268(4):609-14 